\title{
Pengaruh Coaching Support Terhadap Kepatuhan Penderita Chronic Kidney Disease (CKD)
}

\author{
Susanti $^{1}$ dan Caturia Sasti Sulistyana ${ }^{2}$ \\ 1,2Sekolah Tinggi Ilmu Kesehatan Adi Husada \\ susanti@adihusada.ac.id¹ dan caturia @adihusada.ac.id²
}

Diajukan 31 Agustus 2020 Diperbaiki 1 Desember 2020 Diterima 2 Desember 2020

\section{ABSTRAK}

Latar Belakang: Salah satu langkah yang sangat penting untuk kelangsungan hidup penderita Chronic Kidney Disease (CKD) yaitu pengaturan diet secara tepat dan pembatasan cairan. Penderita CKD yang tidak patuh dapat berisiko akan mengalami kelebihan volume cairan di dalam tubuh yang dapat mengancam nyawa.

Tujuan: Penelitian ini bertujuan untuk mengetahui pengaruh coaching support terhadap kepatuhan penderita Chronic Kidney Disease (CKD) di RS Adi Husada Surabaya.

Metode: Penelitian ini menggunakan quasi experiment dengan desain pretest posttest with control group design. Responden dalam penelitian ini adalah 40 penderita CKD dan dibagi menjadi dua kelompok yaitu kelompok kontrol dan perlakuan dengan teknik consecutive sampling. Coaching support diberikan kepada kelompok perlakuan selama dua minggu empat pertemuan. Data dianalisis menggunakan uji statistik yaitu Paired $t$-Test dan Independent $t$-Test dengan signifikansi $\mathrm{p}<0,05$.

Hasil: Hasil analisis menunjukkan bahwa terjadi perbedaan kepatuhan yang signifikan antara kelompok kontrol dan kelompok perlakuan dengan p-value $=0,000$. Intervensi coaching support efektif terhadap kepatuhan penderita CKD. Pelaksanaan coaching support berlangsung dengan baik karena responden dan keluarga proaktif.

Kesimpulan: Terdapat pengaruh antara coaching support terhadap kepatuhan penderita CKD. Coaching support sebaiknya diterapkan oleh perawat sebagai daily activity manajemen penderita CKD pada stadium dini supaya menghambat progresivitas kerusakan ginjal sehingga penderita tidak jatuh pada stadium lanjut.

Kata Kunci: Coaching Support; Penderita Chronic Kidney Disease (CKD); Kepatuhan

\section{ABSTRACT}

Background: One of the very important steps to keep the survival of Chronic Kidney Disease (CKD) patients is proper diet management and fluid restrictions. If CKD patients does not adhere, the patients are at risk of experiencing an excess volume of fluid in the body which can be life threatening.

Objective: This research aims to determine the effect of coaching support on compliance with patients with Chronic Kidney Disease (CKD) at Adi Husada Hospital in Surabaya.

Method: Research quasi experiment with pretest posttest with control group design. Respondents in this study were 40 patients with CKD and divided into two groups, namely the control group and the treatment group with consecutive sampling technique. Coaching support is given to the treatment group for two weeks and four meetings. Data were analyzed using statistical tests namely Paired t-Test and Independent $t$-Test with a significance of $p<0.05$.

Results: The analysis showed that there was a significant difference in compliance between the control group and the treatment group with $p$-value $=0,000$. Interventions are Coaching support effective for adherence of CKD sufferers. Implementation of coaching support is going well for the respondent and family proactive.

Conclusion: There is an influence between coaching support on adherence of patients with CKD. Coaching support should be applied by nurses as a daily activity management for patients with CKD at an early stage so that it can inhibit the progression of kidney damage so that patients do not fall at an advanced stage.

Keywords: Coaching Support; Chronic Kidney Disease (CKD) Patients; Compliance 
PENDAHULUAN

Ginjal memiliki peranan penting dalam mempertahankan volume dan distribusi cairan sebagai salah satu organ vital didalam tubuh. Chronic Kidney Disease (CKD) merupakan penyakit akibat ginjal tidak menjalankan fungsinya, maka diperlukan penatalaksanaan komprehensif bagi kelangsungan hidup penderita (PERNEFRI, 2014). Pengaturan diet secara tepat dan pembatasan cairan pada penderita CKD merupakan langkah awal untuk mencegah terjadinya kelebihan volume cairan di dalam tubuh yang dapat mengancam nyawa penderita. Salah satu permasalahan yang terjadi pada penderita CKD adalah kepatuhan. Salah satu contohnya, perilaku penderita CKD yang tidak mematuhi diet dan pembatasan cairan yang sudah direkomendasikan meskipun penderita sudah mengerti dampak yang paling fatal akibat tidak patuh dalam pembatasan cairan (Ariyanti, 2016; Engelke, 2014; NKDEP, 2015).

Hasil yang didapatkan dari data rekam medik RS Adi Husada Surabaya menyatakan bahwa terjadi peningkatan jumlah penderita CKD setiap tahunnya. Terdapat 7 penderita CKD yang melakukan pemeriksaan di poli penyakit dalam tahun 2017 dan di tahun 2019 terdapat 60 penderita CKD, dengan penderita yang melakukan hemodialisis sebesar 20 penderita dan yang dilakukan rawat jalan sebanyak 40 penderita. Ketidakpatuhan penderita CKD dalam diet dan pembatasan cairan yang direkomendasikan menyebabkan banyak penderita yang mengalami tahap lanjut dari CKD dan sekitar $23 \%$ penderita sampai masuk dalam tahap akhir dari CKD (End State Renal Disease).

Pengelolaan masalah kesehatan pada penderita CKD cukup rumit dan dipengaruhi oleh gaya hidup. Ketidakpatuhan merupakan masalah yang sering dialami oleh penderita CKD. Menurut Ramelan et al (2013) tingkat ketidakpatuhan terkait dengan pengaturan diet penderita CKD dipengaruhi oleh dukungan keluarga, tingkat pengetahuan, dan sikap. Menurut Syakira (2013), hal lain yang berpengaruh terhadap ketidakpatuhan penderita CKD dalam pengaturan diet dikarenakan pedoman yang tidak jelas mengenai diet CKD. Penderita CKD harus mengikuti pengobatan, mengikuti diet serta pembatasan cairan (Sirur et al., 2009).

Ketidakpatuhan penderita CKD secara umum terbagi dalam empat aspek yaitu, ketidakpatuhan terhadap program hemodialisis, ketidakpatuhan pada program pengobatan, ketidakpatuhan terhadap restriksi cairan dan ketidakpatuhan mengikuti program diet (Hadiyanti, 2017; Reach, 2011). Terjadinya kegawatdaruratan hemodialisis dikarenakan kelebihan volume cairan di dalam tubuh. Beberapa tanda gejala kelebihan volume cairan adalah terdengar suara ronkhi saat diauskultasi, terjadi penumpukan cairan di dalam paru-paru yang mengakibatkan sesak, terjadi pembengkakan pada kelopak mata dan berat badan yang mengalami kenaikan cukup signifikan (Arici, 2014; Sari et al., 2013). Kondisi tersebut menyebabkan kerja jantung menjadi cukup berat dikarenakan peningkatan tekanan darah dan juga penumpukan cairan di paruparu (Arici, 2014). Selain itu, mortalitas pada penderita CKD juga akan meningkat apabila terjadi peningkatan cairan tubuh $5,7 \%$.

Kesehatan yang optimal merupakan penunjang kehidupan penderita CKD menjadi produktif. Pemberian coaching support ini salah satunya adalah dengan memberikan pendidikan kesehatan secara bertahap dan berkelanjutan dengan memperhatikan masalah-masalah yang dialami oleh penderita CKD sehingga tercapai kesadaran akan penyakitnya dan hasil akhirnya adalah perbaikan perilaku penderita (Wolever et al., 2013).

Tujuan dari penelitian ini adalah 
Pengaruh Coaching Support Terhadap Kepatuhan Penderita...

mengidentifikasi pengaruh coaching support terhadap kepatuhan penderita Chronic Kidney Disease (CKD).

\section{METODE}

Rancangan yang digunakan dalam penelitian ini adalah quasi experiment atau eksperimen semu dengan desain pretest posttest with control group. Popoulasi penelitian ini adalah seluruh pasien CKD di Rumah Sakit Adi Husada Surabaya yang berobat pada April 2020 sampai dengan Juni 2020. Responden dalam penelitian ini adalah 40 penderita Chronic Kidney Disease (CKD) dan diambil dengan teknik consecutive sampling. Pada penelitian ini coaching support merupakan variabel independen dan kepatuhan merupakan variabel dependen. Data dikumpulkan menggunakan lembar kuesioner kepatuhan. Coaching support diberikan kepada kelompok perlakuan selama dua minggu sebanyak empat pertemuan. Uji statistic yang digunakan yaitu uji Paired t-test dan Independent t-test dengan signifikansi $\mathrm{p}<0,05$ yang digunakan untuk mengolah data yang didapatkan.

\section{HASIL}

A. Data umum

1. Jenis Kelamin

Tabel 1. Distrubusi Frekuensi Responden Berdasarkan Jenis Kelamin

\begin{tabular}{llcccccc}
\hline No & $\begin{array}{c}\text { Jenis } \\
\text { kelamin }\end{array}$ & \multicolumn{2}{c}{ Kelompok } & \multicolumn{2}{c}{ Kolompok } & \multicolumn{2}{c}{ Total } \\
& & $\mathrm{N}$ & $\%$ & $\mathrm{~N}$ & $\%$ & $\mathrm{~N}$ & $\%$ \\
\hline 1 & Laki-laki & 6 & 30 & 3 & 15 & 9 & 22,5 \\
2 & Perempuan & 14 & 70 & 17 & 85 & 31 & 77,5 \\
& Jumlah & 20 & 100 & 20 & 100 & 40 & 100 \\
\hline
\end{tabular}

Tabel 1 menunjukkan bahwa sebagian besar yang berpartisipasi dalam penelitian ini berjenis kelamin perempuan, baik pada kelompok kontrol maupun kelompok perlakuan. Responden berjenis kelamin perempuan sebanyak 14 orang $(70 \%)$ pada kelompok kontrol dan sebanyak 17 orang (85\%) pada kelompok perlakuan.
2. Umur

Tabel 2. Distribusi Frekuensi Responden Berdasarkan Umur

\begin{tabular}{|c|c|c|c|c|c|c|c|}
\hline \multirow[t]{2}{*}{ No } & \multirow[t]{2}{*}{$\begin{array}{c}\text { Jenis } \\
\text { kelamin }\end{array}$} & \multicolumn{2}{|c|}{$\begin{array}{c}\text { Kelompok } \\
\text { Kontrol }\end{array}$} & \multicolumn{2}{|c|}{$\begin{array}{l}\text { Kelompok } \\
\text { Intervensi }\end{array}$} & \multicolumn{2}{|c|}{ Total } \\
\hline & & $\mathrm{N}$ & $\%$ & $\mathrm{~N}$ & $\%$ & $\mathrm{~N}$ & $\%$ \\
\hline 1 & $46-55$ th & 7 & 35 & 6 & 30 & 13 & 32,5 \\
\hline 2 & $56-65$ th & 8 & 40 & 8 & 40 & 16 & 40 \\
\hline 3 & $66-75$ th & 5 & 25 & 6 & 30 & 11 & 27,5 \\
\hline & Jumlah & 20 & 100 & 20 & 100 & 40 & 100 \\
\hline
\end{tabular}

Tabel 2 menunjukkan tidak ada perbedaan umur pada kelompok kontrol dan kelompok perlakuan. Sebagian besar responden yang berpartisipasi dalam penelitian ini berada pada kelompok umur 56-65 tahun sebanyak 8 orang (40\%).

3. Pendidikan Terakhir

Tabel 3. Distribusi Frekuensi Responden Berdasarkan Pendidikan

\begin{tabular}{llcrcccc}
\hline No & $\begin{array}{c}\text { Jenis } \\
\text { kelamin }\end{array}$ & \multicolumn{2}{c}{$\begin{array}{c}\text { Kelompok } \\
\text { Kontrol }\end{array}$} & \multicolumn{2}{c}{ Kelompok } \\
Intervensi & \multicolumn{2}{c}{ Total } \\
& $\mathrm{N}$ & $\%$ & $\mathrm{~N}$ & $\%$ & $\mathrm{~N}$ & $\%$ \\
\hline 1 & $\begin{array}{l}\text { Tidak } \\
\text { Sekolah }\end{array}$ & 2 & 10 & 1 & 5 & 3 & 7,5 \\
2 & SD & 3 & 15 & 2 & 10 & 5 & 12,5 \\
3 & SMP & 4 & 20 & 2 & 10 & 6 & 15 \\
4 & SMA & 8 & 40 & 12 & 60 & 20 & 50 \\
5 & Diploma/ & 3 & 15 & 3 & 15 & 6 & 15 \\
& S1/S2 & & & & & & \\
& Jumlah & 20 & 100 & 20 & 100 & 40 & 100 \\
\hline
\end{tabular}

Tabel 3 menunjukkan tidak ada perbedaan latar belakang pendidikan antara kelompok kontrol dan kelompok perlakuan. Sebagian besar responden yang berpartisipasi dalam penelitian ini memiliki pendidikan terakhir SMA yaitu 8 orang $(40 \%)$ pada kelompok kontrol dan sebanyak 12 orang (60\%) pada kelompok perlakuan.

4. Lama Menderita CKD

Tabel 4. Distribusi Frekuensi Responden Berdasarkan Lama Menderita CKD

\begin{tabular}{cccccccc}
\hline No & Lama & \multicolumn{2}{c}{ Kelompok } & \multicolumn{2}{c}{ Kelompok } & \multicolumn{2}{c}{ Total } \\
& CKD & \multicolumn{2}{c}{ Kontrol } & \multicolumn{2}{c}{ Intervensi } & & \\
& & $\mathrm{N}$ & $\%$ & $\mathrm{~N}$ & $\%$ & $\mathrm{~N}$ & $\%$ \\
\hline 1 & $<6$ tahun & 12 & 60 & 11 & 55 & 23 & 57,5 \\
2 & $>6$ tahun & 8 & 40 & 9 & 45 & 17 & 42,5 \\
& Jumlah & 20 & 100 & 20 & 100 & 40 & 100 \\
\hline
\end{tabular}

Tabel 4 menunjukkan tidak ada perbedaan lama menderita penyakit CKD pada kelompok kontrol dan kelompok perlakuan. Sebagian besar responden yang berpartisipasi dalam penelitian ini 
menderita $\mathrm{CKD}<6$ tahun yaitu pada kelompok kontrol sebanyak 12 orang (60\%) dan pada kelompok perlakuan yaitu 11 orang $(55 \%)$.

B. Data khusus

1. Analisis Paired t-test

Tabel 5. Perubahan kepatuhan responden sebelum dan setelah diberikan coaching support

\begin{tabular}{llccccc}
\hline No Responden & \multicolumn{3}{c}{ Kepatuhan } & 95\% & T & $\mathbf{Q}^{*}$ \\
\cline { 3 - 5 } & & $\begin{array}{c}\text { Sebelum } \\
\text { (Mean } \pm\end{array}$ & $\begin{array}{c}\text { Setelah } \\
\text { (Mean } \pm \\
\text { SD) }\end{array}$ & & & \\
& & SD) \\
\hline 1 & Kelompok & $23,93 \pm$ & $25,83 \pm$ & $-1,90 ;$ & 2,44 & 0,00 \\
& Kontrol & 3,68 & 3,14 & $-1,04$ & & \\
2 & Kelompok & $23,93 \pm$ & $29,73 \pm$ & $-5,80 ;$ & 11,2 & 0,00 \\
& Perlakuan & 3,23 & 2,83 & $-4,07$ & 3 & \\
\hline
\end{tabular}

${ }^{*} \mathrm{p}<0,05$ Based on paired $t$-test

Uji Paired t-test pada tabel 5 menunjukkan adanya perubahan pada variabel kepatuhan baik sebelum maupun setelah diberi intervensi dengan nilai $\mathrm{p}=$ 0,00. Nilai $\mathrm{T}$ hitung menunjukkan hasil 11,23 yang berarti terjadi peningkatan kepatuhan lebih besar pada kelompok intervensi dibandingkan dengan kelompok kontrol.

\section{Analisis Independet t-test}

Tabel 6. Nilai selisih kepatuhan responden sebelum dan setelah diberikan coaching support

\begin{tabular}{|c|c|c|c|c|c|}
\hline No & Kepatuhan & $\begin{array}{c}\text { Kelom } \\
\text { pok } \\
\text { Kontro } \\
1 \\
\text { (Mean } \\
\pm \text { SD) }\end{array}$ & $\begin{array}{c}\text { Kelom } \\
\text { pok } \\
\text { Perlak } \\
\text { uan } \\
\text { (Mean } \\
\pm \text { SD) }\end{array}$ & $\begin{array}{c}\text { Mea } \\
\text { n } \\
\text { Diffe } \\
\text { rence }\end{array}$ & $\begin{array}{c}95 \% \mathrm{C} \\
\mathrm{I}\end{array}$ \\
\hline 1 & $\begin{array}{l}\text { Nilai } \\
\text { selisih }\end{array}$ & $\begin{array}{c}1,00 \pm \\
0,98\end{array}$ & $\begin{array}{c}4,80 \pm \\
1,97\end{array}$ & 3,60 & $\begin{array}{c}-4,41 \\
-3,0\end{array}$ \\
\hline
\end{tabular}

${ }^{*} \mathrm{p}<0,05$ based on independent $t$-test

Uji independent t-test pada tabel 6 menunjukkan hasil bahwa $p=0,00$ yang berarti adanya perbedaan perubahan kepatuhan yang signifikan antara kelompok kontrol dengan kelompok perlakuan. Tabel 6 juga menunjukkan nilai mean difference sebesar 3,60 yang menunjukkan adanya perbedaan rata-rata perubahan kepatuhan sebelum dan setelah diberikan coaching support pada kelompok kontrol dan kelompok perlakuan.

\section{PEMBAHASAN}

Hasil pengukuran variabel kepatuhan pada penderita Chronic Kidney Disease (CKD) menunjukkan semua responden pada kelompok perlakuan mengalami peningkatan kepatuhan setelah diberikan coaching support. Hasil paired t-test menunjukkan bahwa terjadi peningkatan kepatuhan pada kelompok perlakuan dan juga kelompok kontrol dengan nilai $p=0,00$. Namun, pada kelompok kontrol hanya terjadi peningkatan sebesar 2,44 sementara pada kelompok perlakuan nilai t hitung lebih besar yaitu 11,23. Kelompok perlakuan mendapatkan intervensi coaching support selama 2 minggu yang artinya coaching support berpengaruh terhadap peningkatan kepatuhan penatalaksanaan CKD.

Uji independent t-test juga menunjukkan perbedaan yang signifikan perubahan kepatuhan pada kelompok perlakuan dan juga kelompok kontrol dengan $p=0,00$ dan nilai $p<0,05$. Responden sebelum diberikan coaching support cenderung mengalami ketidakpatuhan dengan sebagian besar berada pada rentang usia 56-65 tahun. Indikator ketidakpatuhan dapat dipengaruhi oleh usia. Seseorang berusia muda berisiko untuk menjadi tidak patuh karena ketika mengalami sakit kronis orang tersebut akan mengalami konflik dengan pribadinya, sedangkan seseorang yang berusia lanjut lebih bertanggung jawab, lebih tertib, dan teliti, serta cenderung mengikuti anjuran petugas kesehatan dalam mengelola CKD yang diderita (Sari et al., 2013).

Namun, terdapat faktor lain yang melatarbelakangi orang berusia lanjut tidak patuh dalam mengelola penyakit CKD yang dideritanya, diantaranya meliputi ketidakteraturan kontrol dikarenakan penderita kadang lupa minum obat dan obat masih ada sehingga waktu kontrol diundur oleh penderita. 
Pengaruh Coaching Support Terhadap Kepatuhan Penderita...

Alasan lain keterlambatan kontrol dikarenakan tidak ada yang mengantar untuk periksa ke tempat pelayanan kesehatan (Bistara, 2015).

Peningkatan kepatuhan pada kelompok perlakuan banyak dialami responden berjenis kelamin perempuan. Laki-laki memiliki kecenderungan tidak patuh karena banyak melakukan aktivitas yang membutuhkan banyak tenaga atau mengkonsumsi kalori lebih banyak dibandingkan perempuan yang lebih patuh dalam pengelolaan diet (Bistara et al., 2020; Sari et al., 2013).

Hasil penelitian menunjukkan peningkatan kepatuhan banyak dialami oleh responden yang mempunyai pendidikan sekolah menengah atas (SMA). Hal ini sejalan dengan hasil penelitian Sari et al (2013) yang menyatakan bahwa responden yang memiliki tingkat pengetahuan yang baik memiliki peluang untuk lebih patuh dibanding yang berpengetahuan kurang baik.

Faktor lain yang mempengaruhi kepatuhan penatalaksanaan CKD adalah lama menderita CKD. Hasil penelitian didapatkan kepatuhan penderita CKD cenderung rendah pada responden dengan lama menderita $C K D \geq 6$ tahun. Ketidakpatuhan akan semakin meningkat seiring dengan semakin lama penderita mengalami sakit kronis tersebut. Hal ini dikarenakan perubahan keyakinan penderita terhadap efektifitas pengobatan yang dijalani (Bistara et al., 2020;Ramelan et al., 2013).

Perilaku kontrol yang baik terhadap kepatuhan pembatasan asupan cairan dapat dipengaruhi oleh pemberian edukasi atau konseling diet dan cairan (Hadiyanti, 2017). Terapi pengobatan dapat berjalan optimal jika edukasi pasien dalam pengelolaan CKD diberikan secara efektif. Selain itu, kepatuhan dan pengelolaan diri penderita CKD akan meningkat dengan pemberian edukasi yang tepat (Clarke et al, 2016).
Coaching support merupakan metode lanjutan untuk membantu individu mengelola penyakit yang diderita, terutama yang bersifat kronis (Bistara, 2015). Selain itu, coaching support dapat membantu penderita CKD untuk mengubah gaya hidup maupun tanggung jawab atas kesehatan dengan mengidentifikasi isu-isu, kepercayaan, dan kepedulian yang dapat menghalangi ataupun mendukung keberhasilan terapi (Arici, 2014).

Pemberian coaching support dapat mempengaruhi perilaku penderita CKD untuk melakukan pengelolaan penyakit CKD sesuai dengan hal-hal yang sudah disarankan oleh coach (Bistara, 2015). Edukasi pada penderita CKD dengan melibatkan peran serta keluarga dapat diberikan secara langsung maupun secara tidak langsung karena semakin tinggi peran keluarga maka semakin tinggi pula penderita CKD berperilaku patuh terhadap pembatasan cairan dan diet (Thom et al., 2013).

Peningkatan kepatuhan pada penderita CKD dalam pengelolaan penyakitnya dilakukan dengan cara berkomitmen mengubah sudut pandang menjadi positif dengan diawali kesepakatan bersama keluarga dalam proses pelaksanaan coaching support (van Vugt et al., 2013). Peran serta keluarga, lingkungan dan juga responden sendiri menjadi kunci keberhasilan dari intervensi coaching support. Peneliti harus bisa menjadi role model untuk keberhasilan responden dalam meningkatkan kepatuhan (Stacey et al., 2013).

\section{KESIMPULAN DAN SARAN}

Coaching support merupakan salah satu intervensi yang dapat memperbaiki perilaku penderita Chronic Kidney Disease (CKD) yaitu peningkatan kepatuhan dalam penatalaksanaan CKD. 
Pengaruh Coaching Support Terhadap Kepatuhan Penderita...

DAFTAR PUSTAKA

Arici, M. (2014). Management of Chronic Kidney Disease (M. Arici (ed.)). Springer Berlin Heidelberg. https:// doi.org/10.1007/978-3-642-54637-2

Ariyanti, F. W. (2016). Pengaruh Self Efficacy Training Dengan Metode Peer Mentoring Terhadap Self Efficacy dan Kepatuhan Klien End Stage Renal Disease (ESRD) Yang Menjalani Hemodialisis [Universitas Airlangga]. http://repository.unair.ac.id/id/eprint/ 45520

Bistara, Difran N., Rusdianingseh, Susanti, Wardani, E. M., Septianingrum, Y., Ainiyah, N., Fitriasari, A., Noventi, I., \& Hasina, S. N. (2020). Acceptance and commitment therapy (ACT) on increasing the compliance of management diabetes mellitus type 2 . International Journal of Psychosocial Rehabilitation. International Journal of Psychosocial Rehabilitation, 24(9), 942946. https://doi.org/10.37200/IJPR/ V24I9/PR290115

Bistara, Difran Nobel. (2015). Coaching Support terhadap Peningkatan Kepatuhan Penatalaksanaan Diabetes Mellitus Tipe 2. [Universitas Muhammadiyah Yogyakarta]. http:// thesis.umy.ac.id/index.php? opo=bibliography\&id $=62744$

Clarke, A. L., Yates, T., Smith, A. C., \& Chilcot, J. (2016). Patient's perceptions of chronic kidney disease and their association with psychosocial and clinical outcomes: a narrative review. Clinical Kidney Journal, 9(3), 494-502. https://doi.org/10.1093/ckj/sfw014

Engelke, Z. (2014). Patient Education: Dietary and Fluid Compliance for Patients on Hemoialysis. Nursing Practice \& Skill.

Hadiyanti, S. (2017). Pengaruh Self Management Education terhadap Kepatuhan Asupan Cairan pada Klien yang Menjalani Hemodialisis di RSUD Provinsi NTB [Universitas Airlangga]. http://repository.unair.ac.id/66438/
NKDEP. (2015). Chronic Kidney Disease (CKD) and Diet: Assessment, Management, and Treatment. National Kidney Disease Education Program (NKDEP). https:// www.niddk.nih.gov/-/media/Files/ Health-Information/HealthProfessionals/Kidney-Disease/ckddiet-assess-manage-treat-508.pdf? la $=$ en\&hash=AA36A3667129E860429B A1DFD9D61CD9

PERNEFRI. (2014). 7th Report of Indonesian Renal Registry. Indonesian Renal Registry. https:// www.indonesianrenalregistry.org/ data/INDONESIAN RENAL REGISTRY 2014.pdf

Ramelan, M. I., Ismonah, \& Hendrajaya. (2013). Analisis Faktor-faktor yang Mempengaruhi Kepatuhan Pembatasan Asupan Cairan pada Klien dengan Chronic Kidney Disease yang Menjalani Hemodialisis. Jurnal Stikes Telogorejo, 8(3), 22-31. http:// ejournal.stikestelogorejo.ac.id/ index.php/ilmukeperawatan/article/ download/181/205

Reach, G. (2011). Obedience and motivation as mechanisms for adherence to medication: a study in obese type 2 diabetic patients. Patient Preference and Adherence, 5, 523-531. https://doi.org/10.2147/PPA.S24518

Sari, I., Jemadi, \& Hiswani. (2013). Karakteristik Penderita Gagal Ginjal Kronik yang Rawat Inap Di Rumah Sakit Umum Haji Medan, Departemen Epidemologi FKM [Universitas Sumatera Utara]. https:// jurnal.usu.ac.id/index.php/gkre/ article/download/7599/4319

Sirur, R., Richardson, J., Wishart, L., \& Hanna, S. (2009). The Role of Theory in Increasing Adherence to Prescribed Practice. Physiotherapy Canada, 61(2), 68-77. https://doi.org/10.3138/physio. 61.2.68

Stacey, D., Kryworuchko, J., Belkora, J., Davison, B. J., Durand, M.-A., Eden, 


\begin{abstract}
K. B., Hoffman, A. S., Koerner, M., Légaré, F., Loiselle, M.-C., \& Street, R. L. (2013). Coaching and guidance with patient decision aids: A review of theoretical and empirical evidence. BMC Medical Informatics and Decision Making, 13(S2), S11. https://doi.org/ 10.1186/1472-6947-13-S2-S11
\end{abstract}

Syakira. (2009). Konsep Kepatuhan. http:// syakira-blog.blogspot.com/2009/01/ konsep-kepatuhan.html

Thom, D. H., Ghorob, A., Hessler, D., De Vore, D., Chen, E., \& Bodenheimer, T. A. (2013). Impact of Peer Health Coaching on Glycemic Control in Low-Income Patients With Diabetes: A Randomized Controlled Trial. The Annals of Family Medicine, 11(2), 137144. https://doi.org/10.1370/afm.1443

van Vugt, M., de Wit, M., Hendriks, S. H.,
Roelofsen, Y., Bilo, H. J., \& Snoek, F. J. (2013). Web-based self-management with and without coaching for type 2 diabetes patients in primary care: design of a randomized controlled trial. BMC Endocrine Disorders, 13(1), 53. https://doi.org/10.1186/1472-682313-53

Wolever, R. Q., Simmons, L. A., Sforzo, G. A., Dill, D., Kaye, M., Bechard, E. M., Southard, M. E., Kennedy, M., Vosloo, J., \& Yang, N. (2013). A Systematic Review of the Literature on Health and Wellness Coaching: Defining a Key Behavioral Intervention in Healthcare. Global Advances in Health and Medicine, 2(4), 38-57. https://doi.org/10.7453/gahmj. 2013.042 